\title{
Europe in turbulent times? An introduction to this special issue
}

\author{
Sebastian M. Büttner (sebastian.buettner@uni-due.de) \\ University of Duisburg-Essen, Germany \\ Stefan Bernhard (stefan.bernhard@iab.de) \\ Institute for Employment Research (IAB), Germany
}

In the past few years, the process of European integration has gone through a number of serious economic and political turbulences. A decade ago, the breakdown of financial markets has strongly affected both the stability of the common European currency and the cohesion of the European Union as a whole. The economic crisis in Europe, which had initially started with a break-down of credit markets in the U.S. American banking system, quickly jumped over to Europe and revealed numerous structural deficiencies in the design of the European Monetary Union. The so-called "Eurozone crisis" had indeed tremendous repercussions on the socio-economic development and the cohesion of the European continent. First and foremost, it reinforced economic imbalances amongst the members of the Eurozone. The Eurozone crisis hit hard especially countries with weaker economic structures and higher public debts, such as Greece, Portugal, Spain, Italy and Ireland. For some time, the breakdown of the Euro and the Eurozone appeared to be a realistic option. Consequently, almost overnight the Eurozone countries and the European Commission implemented several emergency measures and new regulative structures in order to support the existing monetary system. The political costs of these rescue measures and the heated political quarrels accompanying their implementation, however, are still hard to estimate. The Eurozone crisis has certainly reinforced socio-economic disparities within the European Union, it has strengthened mistrust amongst EU member states (especially between northern and southern EU member states), and it has paved the way for the upswing of anti-EU sentiments, new populist movements, and a stronger polarisation of the political landscape.

Apart from economic turbulences, Europe has been shaken by numerous other turbulences as well, similarly challenging political stability within Europe and the current state of European integration. One major turbulence is caused, for sure, by the rise of political instability and armed conflicts around the external borders of the territory of the European Union: the war in eastern Ukraine in the aftermath of the Orange Revolution, the chain of political upheavals in Arabic countries resulting in a brutal civil war in Syria, the authoritarian turn in Turkey, and the rise of the so-called "Islamic state" in Iraq and other countries in the Middle East. These events triggered another turbulence: the growing migration of refugees and asylum seekers to Europe. These movements posed serious troubles to the existing systems of asylum policy within Europe. Moreover, they provoked political conflicts both amongst and within EU member states regarding the management of migration at a European scale, the appropriate treatment of refugees and asylum seekers, and the conditions of asylum policy in general. The long-term effects of these quarrels and conflicts are still uncertain. It is beyond doubt, however, that these developments have put into question the existing notions and regulations of asylum in many European countries. 
What is more, two other major political events have had direct repercussions on Europe and caused additional turbulences in European politics: the Brexit referendum of June 2016 and the election of Donald Trump as the 58th president of the United States in November of that same year. The Brexit vote clearly marks a crossroad in the history of European integration. For the first time, an EU member state decided to leave the EU thereby breaking with the almost constitutive logic of growing regional enlargement and evermore intensifying integration. Again, the political, economic and social consequences of the Brexit vote remain unclear. Yet, the political and the symbolic consequences of this decision have already been tremendous. The same holds true for the election of Donald Trump, which has - among other things - changed fundamentally the political landscape in world politics and the existing modes and rules of play of international diplomacy. Consequently, in a time of growing disintegration symbolised by the Brexit referendum the EU needs to refocus, work together and develop common solutions.

However, do we really live in turbulent times these days? Is 'turbulence' not just another buzz word standing in a line with 'crises', 'democratic deficit', 'Euroscepticism' and the like? Should we not be careful with exaggerating the current situation by using bold metaphors and dramatizing concepts? For if we look back in history, we easily see that there have been numerous turbulent times in modern European history. Some people would even say that the turbulences Europe faces today are marginal compared to the turbulences it has faced throughout most parts of past centuries. Hence, since social development is always contingent, there is a fundamental phenomenological problem with estimating the significance and the degree of social turbulences. Developments that pose a serious challenge of society in one social situation might represent no serious danger for social stability at another point in time. In contrast to physics, we cannot calculate and provide clear-cut thresholds in social sciences, above which social peace and stability of a certain social fabric is clearly endangered.

Nonetheless, by speaking of turbulences in the current situation, we intend to react to the perception of EU integration as a smooth, stepwise, progressive and somewhat unstoppable process - a perception that the EU promoted itself. Through the logic of 'integration by stealth' (Majone, 2009), conflicts were hedged in by institutional arrangements and backed by common orientations towards continued cooperation. Scientific observers mirrored and reified these perceptions whenever they focused on EU institutional integration and its variations. In other words, conflicts and crises have always been part and parcel of EU integration and our usage of the term 'turbulences' here refers to both this fact as well as to the reluctance of some to acknowledge it.

In that sense, we argue that the difficulties and turbulences the process of European integration faces these days are certainly of a new quality. The current turbulences fundamentally challenge the accomplished status and the trajectories of European integration. It is not only the future direction or next steps of European integration that are widely unclear and highly disputed. More critically, the very idea and the whole concept of European integration seems to be on trial. While European integration has proceeded quite extensively in the past three decades, especially since the fall of the Iron Curtain in 1989 and the introduction of the Common Market during the 1990s, more and more people raise concerns that European integration might have gone too far. While European politics and European institutions have become more important and dominant in our daily lives, more and more people are concerned about shrinking national sovereignty and shrinking possibilities of political participation. These concerns will continue to increase as long as people consider the European Union to be the problem rather than the solu- 
tion. Accordingly, the process of European integration finds itself at a critical juncture where the threat of growing disintegration stands against the opening of new paths of integration.

Either way, the current situation constitutes a watershed moment for the social sciences of European integration, too. It is criticised that the social sciences of European integration were not able to grasp the current dramatic changes, since they had focused too much on incremental institutional changes and endogenous developments. Ivan Krastev (2017) makes this point in his brilliant and provocative essay After Europe. He argues that due to their obsession with integration European studies offered neither satisfactory theories nor analytical conceptions of European disintegration. Consequently, he advocates for a paradigm shift and proposes a post-European research agenda, which straightforwardly maps the symptoms of disintegration and the "implosion" (11), as he puts it, of the existing European project.

While we share the assumption that we need an analytical perspective that is open for the contingencies of European integration and disintegration, we do not follow Krastev in his call for a post-European research agenda. On the contrary, we contend that researchers have adequate analytical means at their disposal, if only they used it. Furthermore, we claim that we should not simply replace the master narrative of European integration by a counter-narrative of 'European disintegration'. The Sociology of European integration and European studies should rather overcome their past shortcomings, in particular their little interest in non-institutionalised conflicts, their focus on the EU (instead of Europe in a wider sense) and their missing willingness to distance themselves from the (self-)interpretations of their research object. It is one of the aims of this special issue to make a step in this direction.

The three original research contributions in this special issue exemplify the richness and variety of current research on Europe and European integration. One way or another, they are concerned with the challenges and turbulences Europe faces today. However, they focus on different topics from different research perspectives and disciplines. Drawing on notions of comparative political economy and liberal intergovernmentalism, the French economist and political scientist Arnaud Lechevalier examines the long-term metamorphosis of "social Europe" and its path through the Eurozone crisis. Lechevalier assumes that the Eurozone crisis offers the opportunity to re-examine the reasons why the European Union has managed to achieve the Single Market and the Monetary Union on the one hand but has failed to reach its social goals and the development a strong social agenda on the other hand. Opposing the established interpretation of a dominance of 'negative' integration over approaches of 'positive' integration, Lechevalier emphasizes the importance of interstate federalism in the structure of decision-making at European level, and he holds that the predominance of market-based approaches to social policy at the European level is an effect of growing economic imbalances and power asymmetries amongst EU member states. Accordingly, Lechevalier explains the predominance of ordoliberal ideas in the management of the Eurozone crisis as following from the dominance of the most powerful EU member states, especially Germany, in the current systems of decision-making at European level. 
Christian Schmidt-Wellenburg's contribution complements Lechevalier's approach and examines European crisis management from another angle. Hence, Schmidt-Wellenburg focuses on the perception of the Eurozone crisis among German-speaking economists. Arguing that economists' knowledge production is crucial for understanding the events around the Eurozone crisis, he distinguishes several discursive currents that each provide a different take on the events of the years 2008 and after. Using Pierre Bourdieu's ideas on the interaction of discursive and social spaces, Schmidt-Wellenburg shows that different groups of economists stand behind the different crisis perceptions. It is this complex interplay of positionings in the field of economists with positionings in the crisis discourse, Schmidt-Wellenburg argues, that moulds the dominant European ordo-liberal position.

With Susann Worschech's contribution the attention moves outside the EU. She deals with public political conflicts in Ukraine that culminated in the Orange Revolution and the so-called Euromaidan protests. Drawing on the works of Charles Tilly and Zygmunt Bauman Worschech develops a multidimensional analytical framework to tackle conflictual and ambivalent processes. In employing that framework, Susann Worschech reconstructs how struggles over the future orientation of the Ukraine crystallised around 'Europe' as a bone of contention and she argues that such processes exemplify ambivalences that are constitutive of all processes of Europeanization.

The original research articles are complemented by a text of the Danish writer Carsten Jensen, who was awarded the first Europa Prize of the Europa-Universität Flensburg in 2018. The text with the title Hjemstavnsløshed (engl.: Home(land)lessness) is Jensen's prize acceptance speech, which he gave at Europa-Universität Flensburg on May 17, 2018. Beyond that, this issue comprises two book reviews: The first review, written by Martin Seeliger, critically engages with the handbook Europasoziologie: Handbuch für Wissenschaft und Studium (engl.: Socioloy of Europe: Handbook for Research and Education) edited in 2018 by Maurizo Bach and Barbara Bach-Hoenig. In the second review, Sebastian M. Büttner discusses Ivan Krastev's book After Europe and identifies major implications that follow from Krastev's book for sociological research on current European transformations.

Last but not least, we would like to thank the editors of the journal for the opportunity to publish this special issue in CPE. We thank Kai Berghoff and Klarissa Lueg for their support throughout the process of publication.

\section{References}

Krastev, I. (2017). After Europe. Philadelphia: University of Pennsylvania Press.

Majone, G. (2009). Dilemmas of European integration: The ambiguities and pitfalls of integration by stealth. Oxford: Oxford University Press. 